\title{
Beyond the performance gap: reclaiming building appraisal through archival research
}

Article

Accepted Version

Patel, H. and Green, S. D. (2020) Beyond the performance gap: reclaiming building appraisal through archival research. Building Research \& Information, 48 (5). pp. 469-484. ISSN 1466-4321 doi:

https://doi.org/10.1080/09613218.2019.1672517 Available at https://centaur.reading.ac.uk/86018/

It is advisable to refer to the publisher's version if you intend to cite from the work. See Guidance on citing.

To link to this article DOI: http://dx.doi.org/10.1080/09613218.2019.1672517

Publisher: Taylor \& Francis

All outputs in CentAUR are protected by Intellectual Property Rights law, including copyright law. Copyright and IPR is retained by the creators or other copyright holders. Terms and conditions for use of this material are defined in the End User Agreement.

www.reading.ac.uk/centaur 
Central Archive at the University of Reading

Reading's research outputs online 


\title{
Beyond the performance gap: reclaiming building appraisal through archival research
}

\author{
Hiral Patel ${ }^{1}$ and Stuart D. Green ${ }^{2}$ \\ ${ }^{1}$ Welsh School of Architecture, Cardiff University, Cardiff, UK \\ ${ }^{2}$ School of the Built Environment, University of Reading, Reading, UK
}

\begin{abstract}
Current debates about building performance evaluation often emphasise the "performance gap' between how buildings perform in practice and how performance was envisaged during the design stage. While such debates continue to be dominated by energy considerations, increasing attention is directed towards the subjective experiences of building users in terms of thermal comfort and wellbeing. The latter trends are undoubtedly to be welcomed, but buildings continue to be conceptualised as fixed physical objects rather than entities that are enacted in practice. With the aim of challenging current assumptions, research is described which sought to reclaim the concept of building appraisal as practised by the pioneering architectural practice DEGW. The concept of building appraisal differs from current notions of building performance evaluation in that the point of departure was not the supposedly fixed entity of the building, but the essential fluidity of the occupying organisation and their aspirations in terms of space. Empirical data is derived from archival sources and through extensive interaction with the DEGW diaspora, many of whom remain active at the leading edge of international practice. It is concluded that the continued fixation with the 'performance gap' reinforces long-since discredited assumptions of environmental determinism.
\end{abstract}

Keywords: building performance, post-occupancy evaluation, qualitative research, building evaluation 


\section{Introduction}

Recent renewed interest in the concept of building performance evaluation (BPE) has been primarily driven by concerns regarding energy efficiency. The imperatives of energy efficiency are however mediated by increasing interest in the subjective experiences of building users in terms of thermal comfort and wellbeing. However, it is too easily forgotten that BPE has a long and chequered tradition, with numerous false dawns along the way (Bordass and Leaman, 2015). There are long-standing recurring questions regarding who should take the lead in BPE, and perhaps more pertinently who should take responsibility for the associated learning. Much of the discussion conceives of buildings as 'composed formal objects' which provide a fixed environment for passive consumption by an identified set of users (Preiser et al., 2015). It is this latter perspective which shapes much of the current debate about BPE, especially that which focuses on the 'technical' aspects of building performance. However, if buildings are viewed as entities which are enacted in practice it becomes necessary to adopt an alternative interpretation of 'performance' as something which plays out over time. It is contended that the time dimension is of central importance to a more nuanced understanding of building performance which extends beyond the narrow constraints of environmental determinism.

The purpose of the described research is to reclaim the tradition of building appraisal as practiced by the pioneering architectural practice DEGW. The guiding research question relates to the extent to which the neglected concept of building appraisal differs from currently accepted forms of BPE. Of particular interest is the extent to which the constituent methods might usefully inform topical debates. It is not the intention to distinguish between 'appraisal' and 'evaluation' in any normative sense. The emphasis lies on the way building appraisal was practiced within the specific context of commercial development in the period immediately preceding the recession of early 1990s. The adopted research method is one of curation through which insights are derived from archival sources (cf. Schoenefeldt, 2019). The research is rendered topical by the continued emphasis within the architectural profession on the need to develop its research base (Samuel, 2017; Till, 2005). However, much of the debate about 'sustaining the knowledge-base of the profession' relates to narrowly defined version of post-occupancy evaluation (POE) whereby the building is reduced to a fixed object (cf. Stevenson, 2019).

The paper is structured as follows. Initially, contemporary notions of building performance are reviewed and critiqued in terms of the recurring tendency towards environmental 
determinism. An alternative frame of reference is offered based on the notion of enacted performance. This provides the basis for critiquing approaches to POE which privilege notions of fixity and permanence. Caution is also expressed regarding the extent to which POE can provide a means of sustaining the knowledge base of the architectural profession. Indeed, it will be argued that the very notion of a 'knowledge base' is misplaced in its inference that knowledge can be conceptualised as a static and monolithic commodity. The focus thereafter lies with the way in which the methods of building appraisal as initially championed by DEGW are presented in the literature. The empirical part of the paper commences with a description of curation as a research methodology and its application to the DEGW archive held at the University of Reading. The findings are presented in the form of a reconstruction of building appraisal as it was conceptualised and enacted by DEGW during the 1980-90s. Finally, connections are made with contemporary concerns. A recurring theme throughout relates to a systemic failure to learn from the past.

\section{Beyond the performance gap}

Current debates about building performance tend to be dominated by the so-called 'performance gap' in terms of energy use (e.g. de Wilde, 2014; Menezes, et al., 2012; Zou et al. 2018). The essential argument is that occupied buildings routinely do not perform as anticipated at design stage. Numerous reasons have been put forward to explain this supposed 'gap', including inadequate modelling and faulty on-site installation of energy technologies. Such debates are too often characterised by a naïve form of 'environmental determinism' (cf. Vischer, 2008). There is seemingly a strong recurring assumption that design choice will dictate the behaviour of those who occupy the building. Even those researchers who emphasise the 'unintended consequences' of energy interventions seem to do so with a mild sense of surprise (e.g. Shrubsole et al., 2014).

The current fixation with energy performance further risks being regressive in the sense that it commodifies space solely in terms of the associated energy cost. Even the very notion of energy efficiency is not without its critics. Shove (2018) argues persuasively that energy efficiency, as currently constituted, risks undermining the very thing that it purports to achieve, i.e. a reduction in carbon emissions. The essence of Shove's position is that the everincreasing focus on energy efficiency deflects attention from the socio-material practices which shape energy demand. The argument in part relates to the so-called rebound effect whereby 'savings' realised through energy efficiency translate into a demand for higher-level 
services, i.e. higher levels of thermal comfort. The issue here is that energy usage does not depend solely on how buildings are designed, or the 'advanced' technologies which are incorporated. Even on the single criterion of energy, building performance is a more complex phenomenon than is commonly presented, and cannot meaningfully be judged against any notion of a 'gap'.

Cole et al. (2008) have also been influential in arguing that improving environmental performance requires an understanding of the dynamic interaction between the building and its inhabitants. Of particular note is the advocated concept of 'interactive adaptivity' which seeks to take account of both context and human agency. The focus lies on how interactions play out over time, spanning from design through to construction, and especially throughout occupancy. Yet in common with others whose interests are shaped by building physics, Cole et al. are primarily interested in environmental performance as enshrined within the green buildings concept. Their interests spill over into thermal comfort and increasingly into the broader domain of wellbeing. However, they are seemingly less interested in building performance in its broader sense, i.e. the extent to which buildings contribute to the operational performance of the occupying organisation.

Tweed and Zapata-Lancaster (2017) offer an extended review of current approaches to BPE, including: BREEAM In-Use (BRE, 2016), LEED Operations and Management (USGBC, 2017) and 'Soft Landings' (BSRIA, 2015). They contend that such approaches are largely conceived as technical methods of assessing buildings as physical assets against predetermined technical performance criteria. They further note that 'failure' tends to refer to unsatisfactory environmental conditions (cf. Bluyssen, 2009; Vischer, 2008). As an alternative, Tweed and Zapata-Lancaster (2017) advocate a humanities-based approach to understanding 'thermal experience' based on phenomenology. The emphasis hence shifts away from assessing the energy cost of space towards understanding the experience of individual building inhabitants. Yet there is again little interest in performance on the level of the organisation, i.e. the extent to which the space might be perceived to be 'adding value' to the occupying organisation. Interest in building appraisal in this latter sense seems to have diminished in direct inverse proportion to the burgeoning interest in energy performance. Markus (2001) has previously observed that the long tradition of BPE has tended to focus almost entirely on subjective responses to noise, lighting, glare and thermal comfort. $\mathrm{He}$ attributes this bias to its origins in building physics. Thermal experience may well be an important component of wellbeing, but any effective approach to building appraisal must 
surely extend to performance on the level of the organisation. It is this latter component which is so often missing from current debates.

\section{Buildings as enacted in practice}

It is of course not new to argue against the assumptions of environmental determinism. Frank Duffy $(1970 ; 1974)$ was making such arguments as long ago as the early 1970s. Yet the widespread belief that building performance can be pre-determined through design remains remarkably intact despite repeated refutations. Indeed, the debate seems to be re-visited with each subsequent generation, only to be subsequently forgotten prior to being 'discovered' anew (Markus, 2001). Van Marrewijk and Yanow (2010a; 5) are especially strident in arguing the need for alternative theoretical foundations:

"[a] treatment of the intentions of organizational leaders and their architects that assumes that design elements will shape employees' and others' behaviours without according them agency of their own...... is, today, theoretically and intellectually untenable."

In seeking an alternative theoretical foundation for the concept of building performance, we seek to build on the arguments of those who have previously advocated the cause of practice theory. Although practice theory is by no means homogeneous, the central focus lies on understanding that social phenomena are fluid entities which are forever shaped and reshaped on the basis of a myriad of socio-material practices (Nicolini, 2012). The same logic can be applied to buildings, which in turn leads to a very different understanding of building performance. There is an established trajectory of practice-based research in the particular context of energy use (Chiu et al. 2014; Karvonen, 2013; Shove, 2018; Shove and Walker, 2014). Chappells and Shove (2005) specifically apply practice theory to the study of thermal comfort with an emphasis on the socio-material practices of building occupants. Lowe et al., (2018) also touch upon practice theory in their advocated socio-technical systems approach to building performance evaluation. However, to date there has been few attempts to apply practice theory to the broader concept of building performance in organisational terms.

Notwithstanding the above, the continued tendency amongst those interested in the technical aspects of building performance is to view building as fixed entities. An alternative perspective would be to theorise a building as being in continuous flux over time, thereby 
emphasising the myriad of adaptations that occur throughout a building's lifespan (cf. Latour and Yaneva, 2008). Yet there remains very little interest in understanding buildings in terms of the ongoing enactment of socio-material practices (Patel and Tutt, 2018).

\section{The diminishing returns of post-occupancy evaluation}

A strong recurring theme in the literature relates to the evaluation of building performance at the post-occupancy stage, invariably referred to as post-occupancy evaluation (POE). It is notable that performance evaluation based solely on energy use was deemed not to qualify in the early days of POE development (Preiser at el., 1988). Riley et al. (2010) provide a good overview of the development of POE in the UK, commencing with the pioneering role of Building Performance Research Unit (BPRU) at the University of Strathclyde in the 1960s. The history of POE thereafter is best described as chequered, and it has long-since faced significant institutional barriers to adoption (Stevenson, 2019). While precise definitions of POE are contested, Preiser and Vischer (2005) remain influential in their emphasis on the evaluation of the extent to which a building meets the needs of its 'users'. Typical issues of concern include: occupant performance, worker satisfaction and productivity. Such concerns hark back to models of organisational performance rooted in the 1960s. Indeed, all three of the cited 'typical issues' are difficult enough to measure in their own terms irrespective of any supposed causal connectivity with the physical environment within which they take place. Notions of 'diagnostic tools' for the purposes of evaluating occupied buildings further run the risk of creating expectations which cannot be satisfied; hence the 'diminishing returns' of POE.

Of particular note within the dominant interpretation of POE is the entirely passive role often accorded to 'users', and the assumed technocratic process of satisfying their supposed needs. Riley et al. (2010) further observe that the phrase POE is in itself misleading in that it gives the impression that it should be completed as a one-off exercise once the building is occupied. It has of course long since been argued that POE should be understood as part of a broader commitment to 'building performance evaluation' which continues throughout the building's life-cycle (Coleman et al, 2018; Preiser et al. 2005; Stevenson, 2019). Here lies another argument which is repeatedly made, and repeatedly forgotten.

Perhaps the most influential series of POEs was the so-called PROBE studies which were conducted from 1995-2005 (Bordass and Leaman, 2015). PROBE was an acronym for 'PostOccupancy Review of Buildings and their Engineering', although this implies a narrower 
technical focus than was justified. Of particular note was the POE conducted in 1998 of the Elizabeth Fry Building at the University of East Anglia. The building, commissioned in 1995, attracted much attention during the late 1990s for achieving excellent energy performance with good levels of thermal comfort (Standeven et al., 1998). In 2011, the PROBE team returned to re-evaluate the building's performance (Bordass and Leaman, 2012). They were struck by the extent to the building's spaces had undergone substantive changes since they were initially evaluated. Perhaps the most striking finding was the significant increase in occupant density such that the two studies were no longer comparing like-with-like. The emergent questions related much less to the way design choice had shaped energy performance and thermal comfort, and rather more to the consequences of the unanticipated increase in occupant density.

In recent years the PROBE legacy has been sustained through the 'Soft Landings' approach as promoted (and commercialised) by the Building Services Research and Information Association (BSRIA). The initiative has undoubtedly been successful in bringing the benefits of POE to a much wider audience, but the focus on handover and 'extended aftercare' has arguably served to reinforce the recurring assumption that buildings are in essence fixed entities. The Soft Landings approach was initially developed by Mark Way with the limited aim of ensuring that occupiers could operate the building systems in accordance the designers' intentions (Way and Bordass, 2005). The contention is that design and construction teams should remain involved beyond practical completion for the purposes of fine-tuning the building's operation. The subsequent involvement of BSRIA inevitably served to reinforce the original emphasis on environmental and energy performance. It is notable that the formal published Soft Landings framework (BSRIA, 2009) was authored by Mark Way and Bill Bordass, with assistance from Adrian Leaman - a key member of the PROBE team with strong links to DEGW. Despite this impressive pedigree, the expressed commitment to POE is limited to a three-year period of extended aftercare.

An associated development was the launch of 'Government Soft Landings' by the Cabinet Office (2013) as part of the UK Government's strategy for the public sector adoption of BIM. This version had a much stronger focus on economic and social outcomes, including issues relating to functionality and effectiveness. More recently, there has been a convergence between Government Soft Landings and the BRISA approach described above (BSRIA, 2015). Both initiatives have been important in normalising POE, and on this basis they should be welcomed. However, Soft Landings still tend to focus on the more tangible elements of 
building services (Gillen et al., 2019). The primary limitation is that buildings continue to be conceptualised as fixed technical artefacts. Hence the point of departure remains stubbornly focused on the building itself, rather than the socio-material practices of the building occupants. There is also seemingly a continued assumption that future end-user expectations can be discounted into the present. The dominant framework of environmental determinism hence remains essentially intact.

\section{Sustaining the knowledge base of the profession}

Recent years have seen an increased interest in sustaining the 'knowledge base' which underpins the architectural profession (Collins, 2014; Samuel, 2017) Although there is an explicit recognition of the primacy of 'knowing-in-practice', the advocated direction of travel is seemingly towards the development of a formally codified knowledge base. It is from this starting point that POE is conceptualised as a form of research through which such codified knowledge can be developed (Collins, 2014). Hay et al. (2017) describe a series of POEs as implemented by architectural practices, the majority of which are one-off exercises. The emphasis lies on single buildings and how they perform against predetermined criteria. This same emphasis is evident in the approach advocated by the RIBA (2016).

The recurring tendency to evaluate performance against a pre-determined set of criteria is indicative of single-loop learning. The learning derived from such comparisons is not of course without value, but it is surely also necessary continuously to question the criteria against which performance is evaluated. Without constantly reviewing the criteria of performance evaluation there is a danger that the resultant knowledge becomes ossified and irrelevant. The same critique also applies to the repeated use of standardised occupant surveys (Chiu et al., 2014). There is hence a need to extend beyond the short-term aspirations of individual 'users'. Ossification of the resultant 'knowledge' would be avoided by the continuous questioning of the adopted performance criteria. Indeed, such a shift to doubleloop learning could be construed as an essential component of professionalism (Argyris and Schön, 1978).

Similar arguments are made by Stevenson (2019), who notably goes one stage further in advocating BPE as a means of 'deep' triple-loop learning. Such arguments are undoubtedly compelling, but the primary concern remains the extent to which the resultant knowledge can be 'fed-forward' for the benefit of supply-side professionals on subsequent projects (Gillen et al., 2019; Hay et al., 2017). In contrast, practice-based theorists such as Nicolini et al. (2003) 
see 'knowing' as inherently social, and uniquely situated in spatio-temporal contexts. We must therefore be cautious of the dangers of commodifying 'knowledge' as being easily transferable across time and space (Orlikowski, 2002).

It must further be recognised that any conversation about the 'knowledge' derived from POE very quickly becomes politicised. For example, design architects invariably have a direct vested interest in 'talking up' the importance of design. Space planners likewise have a vested interest in emphasising the significance of their own services. This is similarly true for the other built environment professions. Hence disinterested 'research-based' evidence remains in remarkably short supply. An additional complication is provided by the vagaries of boundary definition; knowledge relating to building performance evaluation is by no means the sole concern of any single profession. The critical point is that organisational knowing is distributed amongst multiple actors all of whom learn continuously from everyday practice. A particularly pointed criticism of POE is that it tends to be the professional team which decides what is measured rather than the building occupants (Wood, 2018). Hence it is the values of the professional team which are forever replicated. The inevitable consequence is that the interests of building users are too easily subjugated to the cause of enhancing the status of the professional team (cf. Sachs, 2013).

\section{The ongoing legacy of DEGW}

Prior to introducing the practices associated with 'building appraisal' it is appropriate to provide a brief overview of DEGW. The adopted focus on DEGW is justified by their widespread recognition as pioneers in the associated fields of space planning, building appraisal and facilities planning \& management (Symes et al., 1995). DEGW was originally established in London in 1971 with four founding partners: Frank Duffy, Peter Ely, Luigi Giffone and John Worthington. From relatively modest beginnings, the firm expanded to work for a range of corporate and government clients internationally. At its peak it had offices in the UK, US, France, Germany, the Netherlands, Spain, Italy, Singapore and Australia (Duffy et al., 1998). However, the firm fell into financial difficulties during the recession of the early 1990s and never quite fully recovered. It was eventually taken over by the Dutch consultancy Twynstra Gudde in 1998 only for the DEGW management to buy it back in 2001. The firm again struggled for financial viability prior to being sold to the quantity surveying practice Davis Langdon in 2009. Davis Langdon was subsequently 
acquired by AECOM in 2010 where the legacy of DEGW continues as Strategy Plus. Building appraisal as originally advocated by DEGW endures within the legacy practice within AECOM, and indeed more widely as a result of the continued influence of the DEGW diaspora.

DEGW played a key role in establishing 'workplace strategy' as a distinctive sub-discipline and sought to differentiate themselves from their competitors on this basis. They remain unusual in that so much of the thinking which shaped DEGW's practice is available in the published works of Frank Duffy (and colleagues). The underpinning ideas relating to the importance of 'time' can be traced back to at least the early 1970s (e.g. Duffy and Worthington, 1972). It was this recognition of the importance of time which led to the DEGW practice of specifying different life-spans, or rates of change, for different building elements (Duffy et al., 1976). Duffy and colleagues argued consistently that buildings only exist "to allow people to do what they want to do" (Duffy, 1998a, p.9; first published 1968). Their telling observation was that buildings too often fail even in this most basic of respects. This is the performance gap at its most rudimentary level.

\section{Building appraisal as described in the literature}

The antecedents of the DEGW approach to building appraisal can be traced back to a series of appraisals published in the Architects' Journal during the 1970s (Duffy, 1975a; 1975b; 1976; 1977; 1978). However, its peak period was 1988-1993 when DEGW were involved in the appraisal of over 200 significant office buildings (Duffy, 1993). Key projects included the prestigious developments at Broadgate and Stockley Park. The underlying thinking owed much to the ORBIT studies which investigated the impact of the information technology (IT) revolution on the prevailing standards for office space (Duffy, 1998b; first published 1983). This was sectoral-level research on a much more ambitious scale than 'feeding forward' the lessons from individual projects through POE. Data on shifting trends in office requirements were sourced through a variety of means, not least through the use of focus groups with potential clients from the financial sector. Duffy (2009) contends that these focus groups were given a critical edge as a direct consequence of office standards at the time being so poor.

Of further relevance within the literature is DEGW's engagement with the then still-emerging discipline of organisation studies. The influence of Burns and Stalker (1961) is evident in the 
recognition that the mechanistic organisations of the past were giving way to more organic forms of organising:

"The point is that this distinction seems not to be accidental but to be related to the nature of the task, to the environment of the enterprise and particularly to the rate of technical innovation." (Duffy, 1970, p.326)

It is notable that very few contemporary architectural practices express any interest in organisation studies, which is likewise given scant attention in architectural education. But for DEGW it was not just a case of designing to accommodate future needs; buildings were crucially seen to comprise organisational change programmes in themselves (Bradley and Osborne, 1999). This was indeed a case of viewing architecture through an entirely different lens.

An early underlying principle of building appraisal was the need to analyse buildings according to their capacity to be used in different ways by targeted sets of users (Duffy, 1998b (first published 1983). At the very core of DEGW's approach was the recognition that different organisations have different requirements. It was argued that generic design guidelines can be helpful in a stable business and technological environment, but in periods of rapid change the ossification of standards can become dysfunctional (Bordass and Leaman, 2015). Indeed, in retrospect, Duffy (2009) concedes that the DEGW approach to building appraisal progressively lost its critical edge as it became routinized. Following the early 1990s recession, it also became ever more commercially challenging to sustain the necessary underpinning research. Beyond the writings of Frank Duffy and his colleagues, there remains little independent empirical evidence of the way building appraisal was implemented in practice.

\section{Curation as research methodology}

The adopted research methodology hinged around the curation of the DEGW archive as acquired by the University of Reading in 2016. The archive comprises approximately 800 documents relating to DEGW's client-facing activities from 1971 to 1997 . It is complemented by the personal collections of Frank Duffy and Luigi Giffone. The adopted approach to curation extended beyond the preservation of the archive's contents to an active dialogue with members of the DEGW diaspora, including those in the legacy practice within AECOM. The approach is captured in the idea of a 'living archive' which emphasises the use of the archive as a means of stimulating an active dialogue around the questions which the 
present puts to the past (Hall, 2001). The DEGW diaspora played an important role in relating the archive to contemporary concerns. Curation was hence conceptualised as a socialised process of knowledge co-production (Puwar and Sharma, 2012; Kreps, 2003). Activities such as exhibitions were construed as sites for knowledge creation rather than as passive means of dissemination (Basu \& Macdonald, 2007; Obrist, 2014). There is of course a long-established tradition of exhibitions within architecture. They are often presented as a means of ensuring that architectural criticism remains relevant and impactful (Gadanho, 2015). To the authors' best knowledge, there has been no previous use of exhibitions as a research method in the specific context of building appraisal.

\section{Curation activities}

The curation process took place over an 18-month period commencing in May 2016 and continuing until November 2017. It included a series of pop-up exhibitions, participative seminars and focused discussion groups. Of particular note was a guided walk around the Broadgate development in London with key members of the DEGW diaspora. These activities were actively curated in collaboration with members of the DEGW diaspora leading to an emergent understanding of building appraisal as practiced during its peak period of 1988-1993.

The first exhibition took place on $27^{\text {th }}$ October 2016. It sought to place building appraisal in the evolving context of DEGW's methods and concepts. It was accompanied by a public lecture by DEGW co-founder John Worthington. Invitations were sent to ex-DEGW employees and the event was actively promoted to members of public. 165 people registered for the lecture, many of whom visited the accompanying exhibition. The outcomes from this initial event were used to populate a questionnaire survey entitled 'Tracing the DEGW network'. The purpose of the survey was to map members of the DEGW network globally and to identify the concepts and methods which they considered important. The survey was sent to 102 professionals who had at some stage of their career worked for DEGW. Fifty responses were obtained, of which ten respondents had been involved in the delivery of building appraisal. The respondents were also asked to identify the DEGW projects that they considered most influential.

A further event took place on $16^{\text {th }}$ June 2017 and was construed as part of the 'memory' theme of the London Festival of Architecture (LFA). It comprised a pop-up exhibition at AECOM's London office in Aldgate together with a guided walk around the Broadgate 
development. Broadgate had been identified in the survey as being amongst the most influential of DEGW projects. It also had the advantage of being easily accessible from the exhibition venue.

The curatorial process of crafting the Broadgate walk involved detailed discussions with several former senior members of DEGW, most notably John Worthington (founding partner), Despina Katsikakis (former chairperson). The researchers' understanding of the broader context was also aided through a filmed interview with Sir Stuart Lipton ${ }^{1}$. The preparation for the Broadgate walk also involved the analysis of archival materials and other sources which were made available by the participants. In accordance with accepted convention, specific sources from within the DEGW archive are referenced with footnotes. The materiality of the Broadgate site itself was important in stimulating discussion and hence shaping the curatorial process. Three anchor locations were selected at the Broadgate site, each relating to a corresponding theme. A digital map of the walk was created for the purpose of sharing information with the participants prior to the walk.

The Broadgate walk involved 13 participants including three former members of DEGW who were directly involved in the Broadgate project. Three participants were engaged with more recent redevelopments of Broadgate and surrounding areas thereby enabling a conversation which spanned from the past to the present. The remaining seven participants were interested professionals who had responded to the public invitation.

\section{Understanding the enacted practices of building appraisal}

Initial discussions with members of the DEGW diaspora suggested from the outset that building appraisal was subject to multiple interpretations, with little apparent consensus in terms of the key methods which were utilised. There was also limited commonality between numerous client-facing documents in the archive which claimed to report building appraisal studies. A degree of clarity was provided by a marketing brochure entitled 'Building

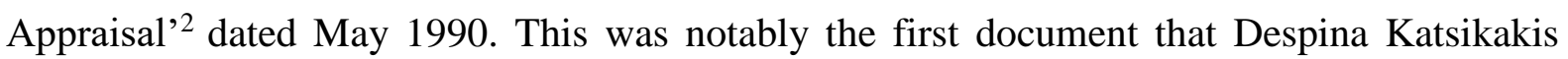
(former DEGW chairperson) pointed to in discussions prior to the Broadgate walk. During

\footnotetext{
${ }^{1}$ Sir Stuart Lipton is widely recognised to have been DEGW's most influential sponsor. He founded Stanhope Properties in 1983, subsequently teaming up with Godfrey Bradman to form Rosehaugh Stanhope Developments (RSD). Lipton is held to have delivered over 20 million square feet of development in London, including Broadgate, Stockley Park and Chiswick Park. His current property company, Lipton Rogers, is responsible for the 22 Bishopsgate development in the City of London.

${ }^{2}$ DEGW Building Appraisal brochure, May 1990. Giffone Collection, University of Reading Special Collections.
} 
the course of the walk, the brochure was used to indicate the breadth of work that DEGW carried out on the Broadgate project. The brochure outlines nine modes of building appraisal grouped under two headings: design process and marketing process. The concept is defined as follows:

\section{“Building appraisal measures an office building's performance in terms of its capacity to meet the present and future requirements of its potential occupants. For the developer, building appraisal helps to ensure the long term utility of the building and hence a maximum return on investment; for the tenant it ensures maximum efficiency and flexibility in the building over time."}

Of particular note is the way in which the service was marketed at both developers and tenants. The antecedents of the approach are evident in several reports within the archive, not least a 1978 consultancy report for Irish $\operatorname{Sugar}^{3}$ on the suitability of their premises. Other examples include a 1981 consultancy report for the accountancy firm Ernst and Whinney ${ }^{4}$ which appraised their headquarters in terms of its suitability for future expansion. Further archival documents from the 1970s confirm the assertion that building appraisal originally evolved as an extension of space planning. Of particular note is the way 'quantity of space' was assessed in terms of space utilization whereas 'quality of space' was appraised in terms of how tenants might use the building. Such arguments were being promoted at a time when the real estate industry tended to evaluate space solely in terms of net lettable area (NLA). Issues of critical concern for DEGW included: layout, depth of space and planning grids. Quality of space in these terms was often evaluated in comparison with other buildings. The building appraisal method was subsequently adapted to inform the emerging concept of business parks 5 .

Taken collectively, the above cited reports provide strong evidence of the building appraisal method maturing over time, not least in response to evolving client requirements. An internal training report from 1995 makes specific reference to a database containing the accumulated details of each appraisal ${ }^{6}$. However, in a focus group discussion several DEGW members dismissed the database was 'mythical', primarily on the basis that such data rapidly became

\footnotetext{
${ }^{3}$ Space Planning and Upgrading of Headquarters in Dublin, Irish Sugar, 1978. DEGW A/160/1

${ }^{4}$ Relating to Becket House, Ernst \& Whinney, 1981. DEGW A/107/2 (1 of 2).

${ }^{5}$ South Wales and the Knowledge Based Industries, Welsh Development Agency, 1982. DEGW/A/452.

${ }^{6}$ DEGW Buildings Database, Training Keynotes, 1995. DEGW/A/86/23.
} 
outdated due to changing market requirements. A recurring resistance to ossification was further confirmed by the DEGW network survey:

"DEGW encouraged you to question and to challenge, to continually look for improvement and always be open to sharing, learning and development.” (Respondent, 'Tracing the DEGW network' survey)

The above expressed orientation towards continuous learning was consistently emphasised over the accumulation of commodified knowledge. Building appraisal as enacted by DEGW was in essence open-ended and under continuous development. The following two sections will appraise the extent to which the archive contains evidence in support of the various activities outlined in the 1990 marketing brochure.

Initially, the five modes of building appraisal will be described as grouped under the label 'design process'. These are broadly understood as practices which actively contribute to the evolving design process. Thereafter, the remaining four modes will be addressed under the label 'marketing process'. The inference here is that the described practices were primarily concerned with marketing the buildings of concern to prospective tenants. However, it is important to emphasise that this classification was transitory with little lasting acceptance amongst the DEGW diaspora. The focus of interest therefore lies with the enacted practices rather than the labels themselves.

\section{Building appraisal modes of application: the design process}

\section{Tenant research}

The espoused aim of tenant research was to understand the needs of identified 'tenant sectors" ${ }^{7}$. Examples within the archive relate to the needs of professional firms and the emerging requirements of the London Stock Exchange. Both studies were commissioned by Rosehaugh Stanhope Developments (RSD) for the Broadgate project. Of particular importance in respect of the second study is a 1986 report entitled Trading in Two Cities ${ }^{8}$. This comprised a comparative study of the trading floors of nine trading companies that had operations in both London and New York. The report built upon an earlier study ${ }^{9}$ specifically focused on New York trading companies. The requirements for trading floors were at the

\footnotetext{
${ }^{7}$ Building Appraisal brochure.

${ }^{8}$ Trading in Two Cities: Design Guidelines for Trading Floors, 1986. DEGW/A/246/19.

${ }^{9}$ New York Trading Floors, 1985. DEGW/A/246/14.
} 
time undergoing significant change. RSD were especially keen to ensure that Broadgate was able to cater for the needs of financial services industry in the context of the 1986 deregulation of the sector ("Big Bang"). Trading in Two Cities was perhaps the most influential of a series of research reports into the accommodation needs of the rapidlyevolving financial services industry in the City of London. The focus of the study was to suggest design recommendations based on the analysis of existing space standards in comparison to what was necessary to support Big Bang. DEGW claimed to be able to test the unsupported claims that were being made at the time in terms of the size of trading floors and other attributes such as layout, ceiling height and cooling loads. But the most important recommendation was to design office buildings that can adapt to changing patterns of use ${ }^{10}$. This latter finding is significant in that it is directly reflective of the DEGW philosophy which comes across so strongly in the literature.

\section{Brief writing}

According to the building appraisal brochure, the espoused purpose of brief writing was to reconcile the performance criteria specified by the developer with those of prospective tenants ${ }^{11}$. Although the archive does not contain any briefs for the Broadgate development, it contains several for the subsequent Chiswick Park development ${ }^{12}$. The legacy of DEGW's approach to briefing is readily discernible in the broader literature (e.g. Blyth and Worthington, 2010). However, the place of client briefing within the broader context of building appraisal is less frequently acknowledged. DEGW were especially influential in advocating a two-stage approach to briefing whereby the 'strategic brief' precedes the development of the 'functional brief'. During discussion, John Worthington was very clear in describing how the DEGW approach to strategic briefing differed from the prevailing norms:

"What we were doing was the strategic brief. The briefs we were doing were very broad. They were basically setting out what the organisation's aspirations are, what it is trying to and putting that in a very simple language ... Once you had agreed the strategic brief, the architect was probably then going to write a functional brief. The functional brief is about expressing requirements in construction terms."

\footnotetext{
${ }^{10} \mathrm{DEGW} / \mathrm{A} / 246 / 19$.

${ }^{11}$ Building Appraisal brochure.

12 A good example of brief writing relates to Chiswick Park project (DEGW/A/278/1 (5 of 10), dated May 1989,
} 
The key point is that strategic briefing was focused on understanding the needs of the organisation rather than performance criteria for the building. Members of the DEGW diaspora were further convinced that they were far ahead of their contemporaries in recognising that corporate clients invariably comprise multiple interest groups. Strategic briefing was hence conceptualised as a participative process involving extensive engagement with a broad cross-section of representatives from within the client's organisation. Indeed, this activity was crucially perceived to be a process which transcended individual construction projects.

In contrast to the above, functional briefs were seen to relate to specific projects. Several respondents recalled that clients such as RSD were notable for developing 'standard' functional briefs which were presented to each design architect at the time of their appointment. The appointed architects were routinely asked to recommend improvements to avoid the dangers of ossification. Gratuitous changes were positively discouraged in favour of a philosophy of 'responsible innovation'. In the context of building appraisal, the important point is that notions of 'performance' were framed through the strategic briefing process in accordance with the business requirements of the occupying organisations. Hence the point of departure was the need to understand the strategic needs of the client organisation rather than the functional needs of any specific building. During discussion, the dominant view amongst the DEGW diaspora was that the distinction between the 'strategic brief' and the 'functional brief' is much neglected in current debates about building performance.

\section{Ongoing consultations}

The brochure also makes reference to a consultancy service which involved the independent evaluation of designs as they evolved in terms of the extent to which they matched a client's requirements ${ }^{13}$. The viability of such a service pre-supposes that the appointed 'design architects' were somehow lacking in the necessary expertise, and that clients were willing to pay an additional fee. John Worthington was again able to bring the archive to life:

"We were popular with the very best design architects because they weren't nervous of their clients. They wanted to understand their clients better and they realised we could help them. At the other end of the scale, the people who came to us with open arms were the commercial architects.

\footnotetext{
${ }^{13}$ DEGW Building Appraisal brochure.
} 
They wanted somebody who could talk the client's language and help them through the process."

Such 'consultations' were compared in discussion with the 'design crit', a ritual deeply embedded within architectural education. However, the dominant view of the research participants was that such 'crits' tend to be led by issues of aesthetics and as such are only rarely informed by research relating to sectoral trends in user requirements. That DEGW were able to perform such evaluations in tandem with leading design architects is indicative of the status they enjoyed at the time.

\section{Building evaluation}

The brochure notably describes 'building evaluation' as an activity focused on ensuring maximum efficiency in the utilisation of space. Issues of concern are indicated to include the quantity and quality of space $^{14}$, capacity for sub-tenancy and appropriate zoning of services. Such evaluations were reportedly widely applied throughout the Broadgate project, although the specific examples in the archive relate to the subsequent Stanhope development at Chiswick Park. Building evaluation studies were apparently most frequently commissioned by the developer, although they were also on occasion commissioned by the appointed design architect. For example, the 'building depth' study on the LTE Hammersmith development ${ }^{15}$ was notably commissioned by Foster Associates. This particular study compared four different layout options in terms of their efficiency and potential for subdivision into cellular offices. Although not explicit within the archive, consideration of operating cost would have been included under the label 'building performance'. Issues of energy efficiency would undoubtedly have been affected by the structural shell \& core of the building, although issues relating to fit-out, including the choice of $M \& E$ services, would ultimately rest with the tenants.

It is further clear that the boundaries between different 'modes' of building appraisal were frequently much more blurred than the categories in the brochure might suggest. Indeed, in discussion, many respondents remained resistant to the idea that the brochure was representative of practice. In their understanding, it represented a short-lived codification produced primarily for the purposes of marketing. Some suggested that the various labels

\footnotetext{
14 The terms quantity of space and quality of space are explained in 'Building Comparison' section below.

${ }^{15}$ Hammersmith Development: A report on 'Building Depth’ for Foster Associates, 1977. DEGW/A/116/1.
} 
provide little more than different windows into an interconnected and forever changing flux of ideas which were forever under development.

\section{Tenant evaluation}

The mode of tenant evaluation is described as a means of establishing the viability of an existing building for potential tenants ${ }^{16}$. The emphasis in the brochure lies with the development of detailed profiles of particular tenant categories. In addition to a focus on the short-term needs of such tenants, there is an emphasis on understanding how their needs might feasibly evolve over time. This focus on the importance of time was repeatedly emphasised in discussion with the research participants. Building designs were reportedly frequently refined on the basis of user research conducted with prospective tenants from the financial services sector. Methods included the use of targeted focus groups which were typically convened over lunch. It was suggested by some that this practice was initiated by Sir Stuart Lipton. The idea was to be proactive in reaching out to potential clients rather than passively waiting for them to show an interest. The Workplace Forum (1983-2003) as coordinated by DEGW and the British Council of Offices (BCO) was also an important source of demand-side insights. Such activities are indicative of the way in which more formal research studies were continuously supplemented by less formal conversations with representatives from potential tenants. Although project-specific conversations tended to be convened with the active participation of the developer, there is also evidence to suggest that similar conversations were convened independently by DEGW.

\section{Modes of application: the marketing process}

\section{Building comparison}

As has already been suggested, the categorisation of different 'modes of application' between design and marketing appears in retrospect to be somewhat arbitrary. The espoused purpose of the 'building comparison' mode was to assess the merits of a given development against rival competing schemes. The archive includes a report entitled Eleven Contemporary Office Buildings: A Comparative Study ${ }^{17}$ commissioned by Stanhope in May 1985. The study compared eleven contemporary London buildings (including Broadgate phases 1 and 2). There is clearly a degree of conceptual overlap with the previously described service of

\footnotetext{
${ }^{16}$ Building Appraisal brochure.

${ }^{17}$ Source: John Worthington. A draft of the report can be found in the archive DEGW A/246/15.
} 
'tenant evaluation'. Although Eleven Contemporary Office Buildings was undoubtedly a means of marketing the Broadgate development, the claims made were not without justification. Broadgate was undoubtedly ahead of its time, not least because unlike other developments at the time it was specifically designed to meet the needs of targeted sectors.

Eleven Contemporary Office Buildings includes a glossary which defines the performance criteria against which the buildings were compared. The specific criteria relating to the 'quantity of space' included commonly accepted efficiency measures such as net lettable area (NLA). However, the criteria relating to 'quality of space' sought to assess the potential of the selected buildings to accommodate different layouts. Of particular interest is the manner in which building services were compared across the eleven buildings. For instance, the financial services sector at the time required a significantly larger cooling capacity than was commonly provided. The assessment of 'quality' hence moved beyond generic characteristics towards an understanding of how different configurations could best be matched with a range of user requirements.

Other relevant reports within the archive include a subsequent post-occupancy appraisal ${ }^{18}$ of six of the eleven buildings included in Eleven Contemporary Office Buildings. This study reviewed the extent to which previous assumptions about the needs of the financial services sector remained intact. This continuous testing of assumptions was claimed to have been a recurring theme within the DEGW philosophy of building appraisal. A further relevant study $^{19}$ within the archive from 1991 sought to appraise the Broadgate development in comparison with other contemporary international developments. In the recollection of those involved, this commitment to continuous comparison was an essential part of the DEGW concept of building appraisal. Of particular note is the way in which the buildings were appraised from the perspective of the users.

\section{Indicative layouts}

The archive provides evidence of the way indicative layouts were used to demonstrate how targeted tenants might feasibly occupy a building. Such layouts tended to be speculative in nature. Numerous alternatives would typically have been developed during negotiations with prospective tenants. There is also evidence that RSD often instructed DEGW to conduct an

\footnotetext{
${ }^{18}$ Accommodating financial services: A post occupancy appraisal of One Broadgate \& five other City office buildings, draft version, 1988. Source: John Worthington.

${ }^{19}$ Broadgate in a World Context, 1991. DEGW/A/246/1 (4 of 8).
} 
analysis of the fit-outs as they were implemented. In common with the building comparisons previously discussed, these post-occupancy studies were commissioned to ascertain the extent to which pre-existing assumptions were justified. This recurring theme stands in harsh contrast to current conceptualisations of POE whereby building performance is measured against pre-determined criteria. There is evidence that post-occupancy fit-out analysis was carried out on several Broadgate phase ${ }^{20}$. Perhaps most notable was the analysis which took place on Phase 11 which reveals that the floor layout adopted by Herbert Smith differed from that initially anticipated ${ }^{21}$. This led in turn to a subsequent commission from Herbert Smith to advise on space-planning strategies for their continued occupancy ${ }^{22}$. Such appointments however became much less common following the recession of the early 1990s.

\section{Tenant feasibility}

Tenant feasibility studies focused on the suitability of specific buildings for occupancy by individual clients. Although various reports within the archive intriguingly refer to 'standard performance criteria' there is no evidence of these ever being used in practice. Indeed, the available evidence within the archive points towards the tendency to develop bespoke methods to meet the needs of specific clients. A good example is provided by the March 1992 report on the suitability of Embankment Place and 60 London Wall for occupancy by the European Bank for Reconstruction and Development (EBRD) $)^{23}$. The report makes it very clear that the performance criteria were adopted to suit the specific needs of the client:

$$
\begin{aligned}
& \text { “... in this particular study priority was given to the very particular and } \\
& \text { non-typical requirements of EBRD which are summarised below. These } \\
& \text { were thought to be sufficiently unusual to take precedence over standard } \\
& \text { measures of building performance." (p. 2) }
\end{aligned}
$$

The report further describes how a bespoke template was developed such that additional data could be added to the assessment on an ongoing basis. In October 1991, One Canada Square $^{24}$ and 175 Bishopsgate (including parts of One Exchange Square) ${ }^{25}$ were also assessed

\footnotetext{
${ }^{20}$ Fit out analysis - Broadgate Phase 6, 1990. DEGW/A/246/1/ (5 of 8). Fit out analysis - Bishopsgate Exchange Broadgate Phase 7, 1990. DEGW/A/246/1/ (6 of 8). Fit out analysis -Broadgate Phase 11, 1990. DEGW/A/246/1 (7 of 8).

${ }^{21}$ DEGW/A/246/1 (7 of 8)

${ }^{22}$ Herbert Smith - Space planning strategies, 1994. DEGW/A/139/1 (1 of 2).

${ }^{23}$ EBRD Headquarters: Building Assessment of Embankment Place and 60 London Wall, 1991. DEGW/A/246/6.

${ }^{24}$ EBRD: One Canada Square, 1991. DEGW/A/106/1.
} 
for possible occupancy by EBRD. The former study was commissioned by Olympia \& York Canary Wharf Limited and the latter by RSD. These subsequent studies crucially included an additional criterion relating to the potential for future expansion. Upon submission DEGW were immediately asked to re-assess the various buildings in terms of their ability to accommodate a range of alternative stacking arrangements ${ }^{26}$. EBRD subsequently moved into One Exchange Square in 1992. Notwithstanding any overlap with the previously described mode of 'building comparison', the example of EBRD is notable in illustrating the iterative development of assessment criteria from building to building. As such, it stands in sharp contrast to the narrow instrumental logic which tends to inform current articulations of POE.

\section{Working guides}

The final mode of building appraisal referred to in DEGW's brochure of 1990 is that of 'working guides'. In many ways these would seem a direct precursor to 'Soft Landings' in the provision of technical and operational information to potential tenants. During the Broadgate walk a copy was obtained of the working guide to Broadgate: Bishopsgate \& Exchange Square ${ }^{27}$. The report is dated July 1989 and was aimed at informing tenant organisations of the key features of the Broadgate development. In contrast to Soft Landings, there was a notable emphasis on how the space might be utilised to enhance business goals. The guide included various checklists to address how the occupied premises might meet the expectations of different business units within tenant organisations. In addition to the overall 'corporate checklist', separate checklists were produced for personnel managers, building managers and information technology specialists. Of particular note is the way tenants were explicitly recognised as pluralistic entities comprising different interest groups each of which required a bespoke checklist. The working guide was also aimed to provide an agenda for ongoing discussion about how future developments (and supporting services) could be improved.

\section{Rent review}

Although 'rent review' is not listed within DEGW's building appraisal brochure it is included here because it was mentioned so often in discussion, not least during the process of curating the Broadgate Walk. The view which was offered was that by the early 1990s building appraisal had gained a quasi-legal status. It was argued that its consistent application on the

\footnotetext{
${ }^{25}$ EBRD: 175 Bishopsgate, 1991. DEGW/A/106/2.

${ }^{26}$ EBRD: Revised Blocking Study - One Exchange Square, 1991. DEGW/A/106/3

27 The report was provided by John Worthington.
} 
Broadgate development set standards not only for the design of office buildings, but also for user evaluations more generally ${ }^{28}$. John Worthington recalled that rent review was an important part of mobilising the user perspective for the purposes of building valuation:

"At that stage, rents were entirely built around the rental rates surrounding it. So if my building was in this particular area and that's the highest rent achieved in the next door building, that's what the rental was. Because the rental was seen as the quality of the entrance - how much marble there was and the sort of toilets they had. That was it. It was nothing to do with how you can use the building."

In retrospect, it is remarkable how the valuation process had previously been almost entirely divorced from the user experience of using the building. Evidence of rent review is provided by a 1992 study $^{29}$ commissioned by RSD in respect of Broadgate phases 1, 2 and 4. The study compared these three buildings with ten other contemporary buildings including 175 Bishopsgate (also part of the Broadgate development). The report cites previous user research by DEGW while at the same time emphasising that the appraisal criteria were empirically derived from a continuous process of learning. This kind of research is far removed from that which is usually cited in the context of 'building performance'.

\section{Discussion}

The overall picture of building appraisal which emerges is that of a continuous cycle of activity from the mid-1980s through to the early 1990s. There is much in the data to support the contention that building appraisal is best conceived as an ongoing activity in the context of continuous flux and transformation. DEGW were undoubtedly before their time in their interpretation of buildings as entities which are enacted over time (Duffy and Worthington, 1972; Duffy et al., 1976). Across the various 'modes' of building appraisal there was a consistent orientation towards ensuring flexibility in response to future needs. There was also a notable recurring tendency towards appraising buildings against bespoke sets of criteria according to the specific needs of tenant sectors, or even individual tenants. The supporting user research was typically orientated towards different 'user types' classified by sector.

\footnotetext{
${ }^{28}$ Frank Duffy's paper titled 'Broadgate: Looking Forward' for British Land Company PLC, dated 28 January 1999. Frank Duffy collection, University of Reading Special Collections.

${ }^{29}$ Comparative appraisal of 13 City office buildings, 1992. DEGW A/246/16.
} 
The tenant groups most heavily evidenced in the archive are professional service firms and those involved in financial markets. The latter underwent a period of rapid of change following 'Big Bang' in 1986; hence the tendency to evaluate buildings in terms of the extent to which they could accommodate future technological and organisational change. There is also evidence of a very clear commitment to keeping the underlying principles of building appraisal under constant review. Indeed, there seems to have been a deep-rooted antipathy to the ossification of building standards. There was seemingly an implicit recognition of the situated nature of 'organisational knowing' which predates the subsequent emergence of such ideas within the context of practice theory (cf. Nicolini et al., 2003; Orlikowski, 2002). Such arguments resonate with the notion of the 'reflective practitioner' as advocated by Schön (1983). Yet another concept which seemingly has to be discovered anew by each generation.

The above described orientation towards the future stands in harsh contrast with current mainstream debates about building performance. This is especially true of those that relate to the 'performance gap' in terms of energy use (e.g. de Wilde, 2014; Menezes, et al., 2012; Zou et al. 2018). BPE in this context is too often focused on narrowly-defined 'efficiency' as measured against the original design intent. Despite dissenting voices such as Shove (2018), the shadow of environmental determinism continues to loom large over current debates. The above depiction of building appraisal as enacted by DEGW is starkly at odds with the 'Soft Landings' approach to POE, although there are points of commonality with the underlying philosophy of BPE as described by Stevenson (2019). However, there are also important points of difference - not least in terms of the essential point of departure.

The currently dominant approach to POE tends to evaluate buildings in terms of predetermined technical performance criteria. In contrast, the essential point of departure for building appraisal was the changing needs of potential occupants. Hence the process routinely commenced with an assessment of how a targeted tenant's needs might change over time. It was on this basis that a bespoke set of criteria were derived against which different options could be appraised. Buildings were seen to be in a symbiotic relationship of mutual shaping with the working practices of the building occupants. Throughout the course of the research, members of the DEGW diaspora were consistently clear that for them the 'project' was never (just) about the delivery a building.

Considerations of energy within the DEGW approach to building appraisal centred on the changing socio-material practices of building occupants. Within the context of commercial 
office development, it is the tenants who ultimately bear the energy costs associated with the occupied space. The majority of those relate directly to the tenant's fit-out choices and subsequent patterns of occupation. In this respect it is worthwhile recalling the example of the Elizabeth Fry Building which was originally celebrated for its energy performance with excellent levels of thermal comfort (Standeven et al., 1998). However, the subsequent unenvisaged increase in occupant density negated the possibility of like-for-like comparisons. The overriding philosophy of DEGW was to avoid design decisions which unreasonably constrained the scope for subsequent adaptability. This ostensibly applied to energy considerations in the same way as it did more generally. It was this philosophy which led to an emphasis on different rates of change for different building elements (Brand, 1997).

Notwithstanding the above, there is seemingly little appetite among current built environment professionals for alternative theoretical perspectives which interpret buildings in terms of unfolding socio-material practices. Arguments that design does not predetermine how buildings are used are unlikely ever to be popular with those with a vested interest in design services such as architects and building services engineers. Fixity and permanence are indeed human conceits, but they are understandably perpetuated by those with a vested interest in talking up the importance of design. To be clear, the argument is not that design is unimportant. The contention is simply that too much emphasis on 'front-end' design deflects attention from the socio-material practices of building occupants. This applies even to the specific criterion of energy use (Shove, 2018). The through-life cost of energy is of course important, but it is categorically not simply dependent solely upon front-end design choices. It is rather more dependent upon the ways in which space is managed over time, not least in terms of how activities are organised to maximise demand-side flexibility. Too much emphasis on the design fabric therefore risks distracting from the importance of demand-side flexibility in reducing peak energy demand. Perhaps part of the problem is the way in which design is routinely claimed to be the unique domain of built environment professionals. Design is possibly best conceived as an activity which is forever ongoing, and as such is by no means the preserve of 'designers' as they are traditionally understood.

Part of the difficulty lies in the 'projectification' of construction as the essential market mechanism through which building procurement is organised. This inevitably serves to create separate narratives for building design and building operation. If professional services were consistently organised in-house this would alleviate many of the institutional barriers to building appraisal. However, there is unlikely to be any retreat from the projectification of 
construction, either in the UK or internationally. In this respect, the analysis aligns directly with that of Stevenson (2019). Approaches to POE such as Soft Landings are inherently constrained by the widespread adherence to the 'project' as the essential unit of production. Even public sector clients (with very few exceptions) routinely outsource architectural services thereby reducing the opportunity for continued engagement with buildings over time. Ultimately, it has to be accepted that the institutional barriers which inhibit any wholesale commitment to building appraisal are intrinsic to the neo-liberal economy within which professionals operate.

As an aside to be above, DEGW have been criticised by some for giving material form to global capitalism (e.g. Hirst, 2011; Wainwright, 2010). Till (2005) also refers to the way in which architecture is too easily subjugated to the instrumental production of the capitalist built environment. Similar arguments can of course be made about energy efficiency; the overriding issue arguably relates to the wholesale commitment to economic growth driven by consumerism. More prosaically, in celebrating the DEGW approach to building appraisal, it must further be recognised that it was a relatedly short-lived experiment which was largely dependent upon the patronage of a single influential client. It is ultimately telling that despite their reputation for iconoclastic thinking, DEGW ultimately struggled to be commercially sustainable.

An additional issue which arises is the recognition that even tenants from within the same sector are rarely homogenous. Building appraisal as presented in the archive frequently recognises the pluralistic nature of organisations. This is immediately evident in the 'working guides' mode of building appraisal, but it was also fundamental to the DEGW approach to strategic briefing (Blyth and Worthington, 2010). Different sub-groups within organisations invariably have different interests which need reconciling. Moreover, the approach recognised that all (client) organisations are not the same. Of central importance was the typological classification of different organisations. But crucially, such typologies were never intended to be static. The fit-out analysis studies evidenced in the archive readily illustrate that generic user typologies require constant empirical validation. In consequence, building appraisal should not be understood as a fixed set of methods, but as something which is forever fluid. We believe that this is a message which needs to be heard.

\section{Conclusions}


The stated purpose of the current research was to reclaim the tradition of building appraisal as enacted by DEGW. As was made clear from the outset, it has not been the intention to differentiate between building appraisal and building performance evaluation (BPE) in any normative sense. What is clear however is that the practices associated with building appraisal differ substantively from those associated with currently advocated approaches to BPE, including the much heralded special case of post-occupancy evaluation (POE). The dominant approach to BPE as presented in the literature tends to evaluate buildings as if they are fixed entities. The current emphasis on POE as a means of single-loop learning risks forever replicating assumptions of environmental determinism coupled with narrowlyconstrued forms of instrumental rationality. Efficiency hence becomes the enemy of effectiveness. The mainstream literature on POE consistently casts users in the role of passive consumers rather than active participants.

Current ways of thinking undoubtedly prioritise the design of 'fixed' buildings over the way in which the space is thereafter managed and used. The accepted narratives of "environmental design' arguably say as much about the brand identities of those involved as they do about verifiable achievements in practice. There is undoubtedly an extensive sub-industry devoted to environment assessment methods which continues to shape and condition the way building performance is conceptualised. And there are without question localised benefits to be derived from this technical infrastructure. But the danger is that it forever defects attention from broader interpretations of performance.

Building appraisal as enacted by DEGW offers an alternative vision for how building evaluation might be organised in a rapidly changing world where the criteria of desired performance are continuously renegotiated. The various modes of building appraisal are also consistent with the interpretation of buildings as socio-material entities in a state of continuous becoming. Most tellingly, the point of departure for building appraisal was invariably an organisation in search of improved performance. Buildings are therefore conceptualised as part of a much broader endeavour. In contrast, BPE is more usually framed in response to the material fabric of a building which is conceptualised as a quasi-fixed entity. Many contributors to the current debate remain rooted in building physics, whereas others champion the cause of POE as a means of sustaining the knowledge base of the architectural profession. In contrast, the DEGW tradition of building appraisal is rooted in organisation studies. This is evidenced by their early reliance on the seminal work of Burns and Stalker (1961). Yet the discipline of organisation studies is strangely of little interest for those who 
advocate POE as a means of 'sustaining the knowledge base of the architectural profession'. Particular caution is necessary in terms of the assumption that 'knowledge' is a commodity which is easily transferable across time and space. The increasing recognition of 'practice theory' within organisation studies would seem to offer an alternative theoretical framework for building appraisal. But built environment professionals need to be active participants in such conversations rather than passive recipients. Materiality has to remain of central concern. An important initial step towards an alternative theoretical framework would be to move beyond the reification of 'building users'. Meaningful progress depends upon built environment professionals accepting that design choices do not dictate the ways in which buildings are used, or indeed the energy costs of operating buildings through-life. Many built environment professionals would intuitively agree with such an argument, but alas it is often not in their commercial interests to share such a view with their clients.

\section{Acknowledgements}

We would like to thank AECOM for their kind donation of the DEGW Archive to the University of Reading. We would also acknowledge the contribution and support of former DEGW members in the execution of the described research. Particular thanks are due to John Worthington, Despina Katsikakis and Nicola Gillen. The research was funded by University of Reading Research Endowment Trust Fund.

\section{References}

Argyris, C. and Schön, D. (1978) Organizational Learning: A Theory of Action Perspective. Reading, MA: Addison-Wesley.

Basu, P. and Macdonald, S. (2007) Introduction: Experiments in exhibition, ethnography, art and science. In S. Macdonald \& P. Basu (Eds), Exhibition Experiments (pp. 1-24). Oxford: Blackwell.

Bordass, B. and Leaman, A. (2012) Test of time, CIBSE Journal, March, 30-36. doi: 10.1136/bmj.b1878. 
Bordass, B. and Leaman, A. (2015) Building performance evaluation in the UK: So many false dawns. In W. F. E. Prieser, A. T Davis, A. M. Salama \& A. Hardy (Eds), Architecture Beyond Criticism: Expert judgement and Performance Evaluation (pp. 160-170). Abingdon: Routledge.

Bluyssen, P.M. (2009) The Indoor Environment Handbook: How to Make Buildings Healthy and Comfortable. London: Earthscan.

Blyth, A. and Worthington, J. (2010) Managing the Brieffor Better Design. 2nd edn., London: Spon.

Bradley, S. and Osborne, P. (1999) The working environment: Catalyst or constraint? Journal of Corporate Real Estate, 1(2), 178-190.

Brand, S. (1997) How Buildings Learn: What Happens After They're Built. London: Phoenix Illustrated.

BRE (2016) BREEAM In-Use International Technical Manual, SD221-2016 Retrieved April 2019 , from

http://tools.breeam.com/filelibrary/Technical\%20Manuals/SD221_BIU_International_2015_ Re-issue_V2.0.pdf

BSRIA (2009) Soft Landings Framework, BG 4/2009, Bracknell. Retrieved April 2019, from http://www.bsria.co.uk/download/asset/sl-books-bg-42009-.pdf

BSRIA (2015) Soft Landings \& Government Soft Landings: A Convergence Guide for Construction Projects. BG 61/2015, Bracknell. Retrieved April 2019, from http://www.bsria.co.uk/download/product/?file=6euA3PI0e0g\%3D Burns, T. and Stalker, G. M. (1961) The Management of Innovation. London: Tavistock. Cabinet Office (2013) Government Soft Landings. London. Retrieved April 2017, from http://www.cdbb.cam.ac.uk/Resources/Bimtaskgroupmaterial/GovernmentSoftLandingsSecti on6FacilitiesManagement.pdf

Chappells, H. and Shove, E. (2005) Debating the future of comfort: Environmental sustainability, energy consumption and the indoor environment. Building Research and Information, 33(1), 32-40. doi: 10.1080/0961321042000322762.

Chiu, L. F., Lowe, R., Raslan, R., Altamirano-Medina, H. and Wingfield, J. (2014) A socio- 
technical approach to post-occupancy evaluation: Interactive adaptability in domestic retrofit. Building Research and Information, 42(5), 574-590 . doi: 10.1080/09613218.2014.912539.

Cole, R. J., Robinson, J., Brown, Z. and O'Shea, M. (2008) Re-contextualizing the notion of comfort. Building Research \& Information, 36(4), 323-336. doi:

$10.1080 / 09613210802076328$.

Coleman, S., Touchie, M. F., Robinson, J. B. and Peters, T. (2018) Rethinking performance gaps: A regenerative sustainability approach to built environment performance assessment. Sustainability, 10(12), 1-22. doi: 10.3390/su10124829.

Collins, E. (2014) Architects and research-based knowledge: a literature review. London: RIBA. Retrieved January 2018, from https://www.architecture.com/research

De Wilde, P. (2014) The gap between predicted and measured energy performance of buildings: A framework for investigation. Automation in Construction, 41, 40-49. doi: 10.1016/j.autcon.2014.02.009

Duffy, F. (1970) Interior design: an anthropological approach. Official Architecture and Planning, 33(4), 324-329.

Duffy, F. and Worthington, J. (1972) Designing for Changing Needs. Built Environment, $1(7), 458-63$.

Duffy, F. (1974) Office Interiors and Organizations - a Comparative Study of the Relation between Organizational Structure and the Use of Interior Space in Sixteen Office Organizations. Doctoral Dissertation, Princeton University, NJ, USA.

Duffy, F. (1975a) Wates House. Architects' Journal, 161(15), 763-775.

Duffy, F. (1975b) Centraal Beheer offices, Apeldoorn, Holland. Architects' Journal, 162(44), 893-904.

Duffy, F. (1976) Central Electricity Generating Board new divisional offices, Barnwood, Gloucester. Architects' Journal, 163(26), 1269-1286.

Duffy, F., Cave, C. and Worthington, J. (Eds.) (1976) Planning Office Space. London: Architectural Press.

Duffy, F. (1977) Hillingdon Civic Centre. Architects' Journal, 165(20), 927-944.

Duffy, F. (1978) Three offices, Reading. Architects'Journal, 167(13), 591-604. 
Duffy, F. (1993) Facilities managers and new developments: the experience of Broadgate and Stockley Park. In W. F. E. Preiser (Ed), Professional Practice in Facility Programming (pp. 85-102). New York: Van Nostrand Reinhold.

Duffy, F. (1998a) Architects and the social sciences. In F. Duffy \& L. Hutton (Eds), Architectural Knowledge: The Idea of a Profession (pp. 8-21). London: Routledge, (First published as "Architect, developer, user, government, manufacturer and the office building" in Building Research, July 1968).

Duffy, F. (1998b) Organizations, buildings and information technology. In F. Duffy \& L. Hutton (Eds.) Architectural Knowledge: The Idea of a Profession (pp.80-84). London: Spon, (First published as "Taming the beast from the wild" in Computer Weekly, 19 January 1983).

Duffy, F., Greenberg, S., Myerson, J., Powell, K., Thomson, T. and Worthington, J. (1998) Design for Change: The Architecture of DEGW. Basel: Birkhäuser.

Duffy, F. (2009) Building appraisal: a personal view. Journal of Building Appraisal, 4(3), 149-156. doi: 10.1057/jba.2008.45

Friedman, D. S. (2015) Reflections on Part V. In Preiser, W. F. E., Davis, A. T., Salama, A. M., and Hardy, A. (eds), Architecture Beyond Criticism: Expert judgement and performance evaluation (pp. 265-268). Abingdon: Routledge.

Gadanho, P. (2015) Is curating the new criticism? In W. F. E. Prieser, A. T Davis, A. M. Salama \& A. Hardy (Eds), Architecture Beyond Criticism: Expert judgement and performance evaluation (pp. 46-52). Abingdon: Routledge.

Gillen, N., Dantsiou, D. \& Whitehead, C. (2019) Research-led design. In N. Gillen (Ed.), Future Office: Next Generation Workplace Design (pp. 93-105). London: RIBA.

Hall, S. (2001) Constituting an archive. Third Text, 15(54), 89-92. doi: $10.1080 / 09528820108576903$.

Hay, R., Bradbury, S., Dixon, D., Martindale, K., Samuel, F., Tait, A. (2017) Pathways to POE, Value of Architects. University of Reading, RIBA.

Hirst, A. (2011) Settlers, vagrants and mutual indifference: unintended consequences of hotdesking. Journal of Organizational Change Management, 24(6), 767-788. doi: $10.1108 / 09534811111175742$ 
Karvonen, A. (2013) Towards systemic domestic retrofit: A social practices approach.

Building Research and Information, 41(5), 563-574. doi: 10.1080/09613218.2013.805298.

Kreps, C. (2003) Curatorship as social practice. Curator: The Museum Journal, 46(3), 311323.

Latour, B. and Yaneva, A. (2008) Give me a gun and I will make all the buildings move: an ANT's view on architecture. In A. Yaneva, B, Latour \& R. Geiser (Eds.) Explorations in Architecture: Teaching, Design, Research (pp. 80-89). Basel: Birkhäuser.

Lowe, R., Chiu, L. F. and Oreszczyn, T. (2018) Socio-technical case study method in building performance evaluation. Building Research and Information, 46(5), 469-484 . doi: 10.1080/09613218.2017.1361275.

Markus, T. A. (2001) Does the building industry suffer from collective amnesia? Building Research \& Information, 29(6), 473-476.

Menezes, A.C., Cripps, A., Bouchlaghem, D. \& Buswell, R. (2012) Predicted vs. actual energy performance of non-domestic buildings: using post-occupancy evaluation data to reduce the performance gap. Applied Energy, 97, 355-364.

doi:10.1016/j.apenergy.2011.11.075

Nicolini, D. (2012) Practice Theory, Work, and Organization: An Introduction. Oxford: OUP.

Nicolini, D., Gherardi, S. \& Yanow, D. (2003) Introduction: Toward a practice-based view of knowing and learning in organizations. In D. Nicolini, S. Gherardi \& D. Yanow (Eds) Knowing in Organizations: A Practice-Based Approach, (pp. 3-31). Armonk, NY: ME Sharpe.

Obrist, H. U. (2014) Ways of Curating. London: Allen Lane.

Orlikowski, W. J. (2002) Knowing in practice: Enacting a collective capability in distributed organizing. Organization Science, 13(3,) 249-273. doi: 10.1287/orsc.13.3.249.2776.

Patel, H. and Tutt, D. (2018) This building is never complete: Studying adaptations of a library building over time. In D. Sage \& C. Vitry (Eds), Societies Under Construction (pp. 51-85). Palgrave Macmillan. 
Preiser, W.F.E. Rabinowitz, H.Z., \& White, E.T. (1988) Post-Occupancy Evaluation, New York: Van Nostrand Reinhold.

Preiser, W. F. E. and Vischer, J. C. (2005) (Eds.) Assessing Building Performance. Oxford: Butterworth-Heinemann.

Preiser, W. F. E., Davis, A. T., Salama, A. M. and Hardy, A. (2015) Introduction. In W. F. E Preiser, A. T Davis, A. M Salama \& A. Hardy (Eds), Architecture Beyond Criticism: Expert judgement and Performance Evaluation (pp. 3-19). Abingdon: Routledge.

Puwar, N. and Sharma, S. (2012) Curating sociology. Sociological Review, 60:S, 40-63. DOI: 10.1111/j.1467-954X.2012.02116.x

Riley, M., Kokkarinen, N. and Pitt, M. (2010) Assessing post occupancy evaluation in higher education facilities. Journal of Facilities Management, 8(3), 202-213. doi: $10.1108 / 14725961011058839$.

Royal Institute of British Architects (RIBA) (2016) Post Occupancy Evaluation and Building Performance Evaluation Primer. Available at:

https://www.architecture.com/RIBA/Professionalsupport/Assets/Files/RIBAPOEBPEPrimer. pdf (Accessed: 17 July 2019).

Sachs, A. (2013) Architects, users, and the social sciences in postwar America. In K. Cupers (Ed.) Use Matters: An Alternative History of Architecture (pp. 69-84). Abingdon: Routledge. Schoenefeldt, H. (2019) The House of Commons: a precedent for post-occupancy evaluation. Building Research and Information, 47(6), 635-665. doi: 10.1080/09613218.2019.1547547. Schön, D. (1983). The Reflective Practitioner: How Professionals Think in Action. New York: Basic Books.

Samuel, F. (2017) Supporting research in practice, Journal of Architecture, 22(1), 4-10. doi: 10.1080/13602365.2017.1280288.

Shove, E. and Walker, G. (2014) What is energy for? Social practice and energy demand. Theory, Culture \& Society, 31(5), 41-58. doi: 10.1177/0263276414536746.

Shove, E. (2018) What is wrong with energy efficiency? Building Research \& Information, 46(7), 779-789. doi: 10.1080/09613218.2017.1361746 
Shrubsole, C., Macmillan, A., Davies, M. \& May, N. (2014) 100 Unintended consequences of policies to improve the energy efficiency of the UK housing stock. Indoor and Built Environment, 23(3), 340-352. doi: 10.1177/1420326X14524586

Standeven, M., Cohen, R., Bordass, B. and Leaman, A. (1998) Probe 14: Elizabeth Fry Building. Building Services Journal, April, E20-E25.

Stevenson, F. (2019) Embedding building performance evaluation in UK architectural practice and beyond. Building Research \& Information, 47(3), 305-317. doi: 10.1080/09613218.2018.1467542.

Symes, M., Eley, J. \& Seidel, A.D. (1995) Architects and Their Practices: A Changing Profession. Oxford: Butterworth Architecture.

Till, J. (2005) What is architectural research? Architectural research: three myths and one model. Discussion Paper. London: RIBA.

Tweed, C. and Zapata-Lancaster, G. (2017) Interdisciplinary perspectives on building thermal performance. Building Research \& Information, 45(5), 552-565. doi:

10.1080/09613218.2018.1379815

USGBC United States Green Building Council (2017) LEED v4 for Operations and Management. Retrieved by Tweed and Zapata-Lancaster (2017) May 2017.

Van Marrewijk, A. and Yanow, D. (2010) The spatial turn in organizational studies. In A. Van Marrewijk \& D. Yanow (Eds), Organizational Spaces: Rematerializing the Workaday World (pp. 1-16). Cheltenham: Edward Elgar.

Vischer, J. C. (2008) Towards a user-centred theory of the built environment, Building Research \& Information, 36(3), 231-240. doi: 10.1080/09613210801936472.

Wainwright, E. (2010) The office is always on: DEGW, Lefebvre and the wireless city. The Journal of Architecture, 15(2), 209-218. doi: 10.1080/13602361003791069

Way, M. and Bordass, B. (2005) Making feedback and post-occupancy evaluation routine 2: Soft landings - involving design and building teams in improving performance. Building Research \& Information, 33(4), 353-360. doi: 10.1080/09613210500162008.

Wood, A. (2018) The Politics of Post Occupancy Evaluation: the Example of Schools. In S. Alterator \& C. Deed (Eds), School Space and Its Occupation: Conceptualising and 
Evaluating Innovative Learning Environments (pp 121-134). Leiden, Brill/Sense.

Zou P. X.W., Xu, X., Sanjayan J. \& Wang J. (2018) Review of 10 years research on building energy performance gap: lifecycle and stakeholder perspectives. Energy and Buildings, 178, 165-181. doi: 10.1016/j.enbuild.2018.08.040. 